\title{
FEM numerical analysis of excimer laser induced modification in alternating multi-layers of amorphous and nano-crystalline silicon films
}

\author{
J.C. Conde ${ }^{\mathrm{a}, *}$, E. Martín ${ }^{\mathrm{b}}$, S. Stefanov ${ }^{\text {a }}$, P. Alpuim ${ }^{\mathrm{c}}$, S. Chiussi ${ }^{\mathrm{a}}$ \\ a Dpto. Física Aplicada, Universidade de Vigo, Rúa Maxwell s/n, Campus Universitario Lagoas Marcosende, Vigo, Spain \\ b Dpto. Mecánica, Máquinas, Motores Térmicos y Fluidos, Universidade de Vigo, Rúa Maxwell s/n, Campus Universitario Lagoas Marcosende, Vigo, Spain \\ c Departamento de Física, Universidade do Minho, 4800-058 Guimarães, Portugal
}

\section{A R T I C L E I N F O}

\section{Article history:}

Available online 24 January 2012

\section{Keywords:}

Excimer laser annealing

a-Si

nc-Si

Dehydrogenation

Numerical modelling

\begin{abstract}
A B S T R A C T
UV excimer laser annealing (UV-ELA) is an alternative annealing process that, during the last few years, has gained enormous importance for the CMOS nano-electronic technologies, with the ability to provide films and alloys with electrical and optical properties to fit the desired device performance. The UV-ELA of amorphous (a-) and/or doped nano-crystalline (nc-) silicon films is based on the rapid (nanoseconds) formation of temperature profiles caused by laser radiation that is absorbed in the material and lead to crystallisation, diffusion in solid or even in liquid phase.

To achieve the desired temperature profiles and to optimize the parameters involved in the processing of hydrogenated nanocrystalline silicon $(\mathrm{nc}-\mathrm{Si}: \mathrm{H})$ films with the UV-ELA, a numerical analysis by finite element method (FEM) of a multilayer structure has been performed. The multilayer structures, consisting of thin alternating a-Si:H(10 nm) and n-doped nc-Si:H(60 nm) layers, deposited on a glass substrate, has also been experimentally analyzed.

Temperature profiles caused by $193 \mathrm{~nm}$ radiation with $25 \mathrm{~ns}$ pulse length and energy densities ranging from $50 \mathrm{~mJ} / \mathrm{cm}^{2}$ to $400 \mathrm{~mJ} / \mathrm{cm}^{2}$ have been calculated. Numerical results allowed us to estimate the dehydrogenation process of the different layers and the diffusion of phosphorous (P) in Si layers as well as their structural modifications as a function of the applied laser energy density. Numerical results are compared with exhaustive characterization of the experimental results.
\end{abstract}

(c) 2012 Elsevier B.V. All rights reserved.

\section{Introduction}

Hydrogenated nanocrystalline silicon (nc-Si:H) consisting of a nano-crystalline phase dispersed in an a-Si:H matrix, is a material with growing importance for large area nano-electronic, photovoltaic and biomedical devices. Its use for the development of enhanced new devices in flexible integrated circuit technology has provoked extensive research in a-Si:H and nc-Si:H thin film processing techniques that avoid high substrate temperatures and, in consequence, preserve the interface quality. This is particularly of interest when dopant activation with junction depth control through annealing is aimed [1,2]. In this context, UV-ELA annealing processes have already shown to strikingly improve crystalline fraction and raise doping efficiency in thin doped nc-Si:H films.

The application of the adequate amount of energy density through pulsed laser radiation causes a rapid heating that provokes the $\mathrm{H}_{2}$ desorption from the $\mathrm{Si}$ surface and the bulk material. Thiesen et al. [3-8] have widely analyzed and demonstrated that the

\footnotetext{
* Corresponding author.

E-mail address: jconde@uvigo.es (J.C. Conde).
}

decomposition of dihydrides and trihydrides phases starts at $670 \mathrm{~K}$ (di-), while for the monohydrides at about $810 \mathrm{~K}$ (mono-). On the other hand, as it has been reported by Fahey et al. [9], P only diffuses in silicon through interstitials and dissolves in the lattice with a limited solubility up to $1173 \mathrm{~K}$ (TP3). The values of the diffusion coefficients are varying in a wide range following an Arrhenius type equation, due to the broad temperature range (between $973 \mathrm{~K}$ (TP1) and $1473 \mathrm{~K}$ (TP6)), as determined by Ghoshtagore et al. [10-14]. Moreover for high energy densities, it should be possible to reach the melting point (MP), thus, a steep thermal gradient and a sharp transition from liquid to crystalline phase takes place in a small volume (the first nano-layers) [15-21].

This work presents a numerical analysis of the ArF laser ELA processing of multilayers with alternating a-Si:H(10 nm)/P-doped nc-Si:H(60 nm) films and $710 \mathrm{~nm}$ total thickness on a $\mathrm{SiO}_{2}$ substrates $\left(1290 \mathrm{~nm} \mathrm{SiO}{ }_{2}\right.$ ) (Fig. 1(a)), for a wide range of energy densities. $100<\Phi\left(\mathrm{mJ} / \mathrm{cm}^{2}\right)<400$.

Our attention is focused on the dehydrogenation temperature (DT) of $670 \mathrm{~K}$ (di-DT) and $810 \mathrm{~K}$ (mono-DT) where the greater amount of hydrogen should be liberated; likewise, the temperature between $973 \mathrm{~K}$ and $1473 \mathrm{~K}$, where the P diffusion is important, is analyzed. 
(a)

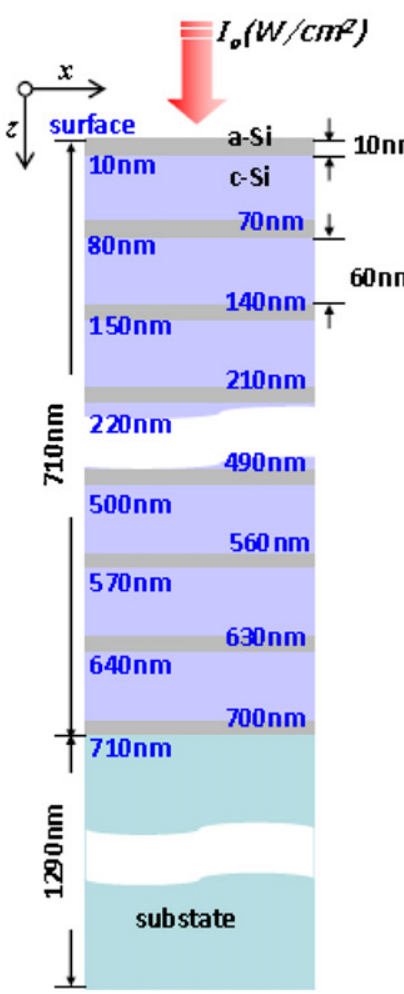

(b)

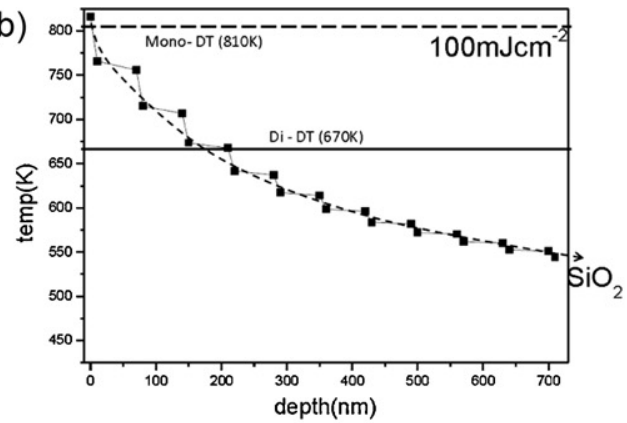

(d)

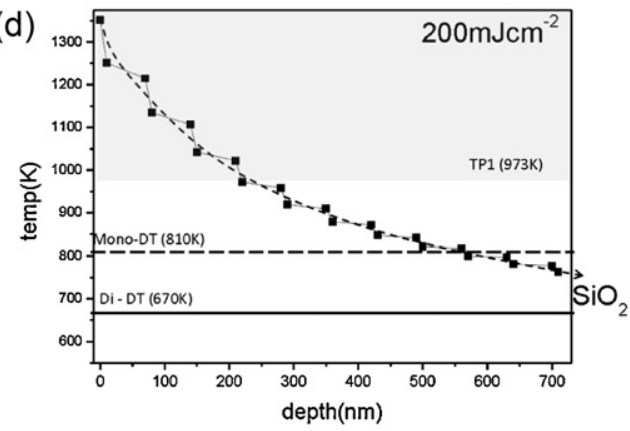

(f)

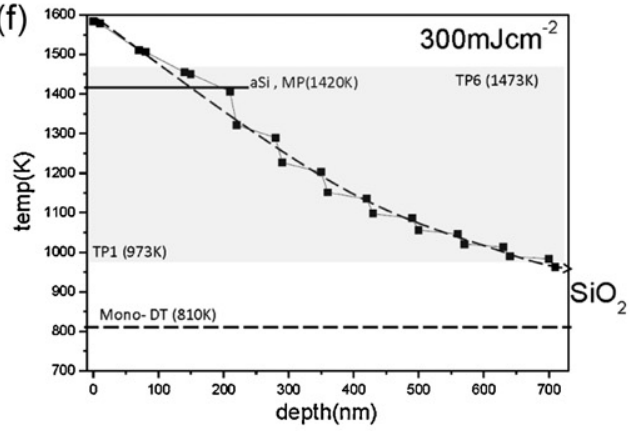

(c)

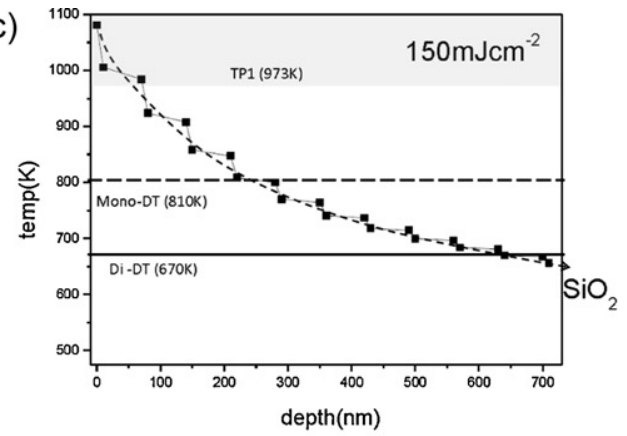

(e)

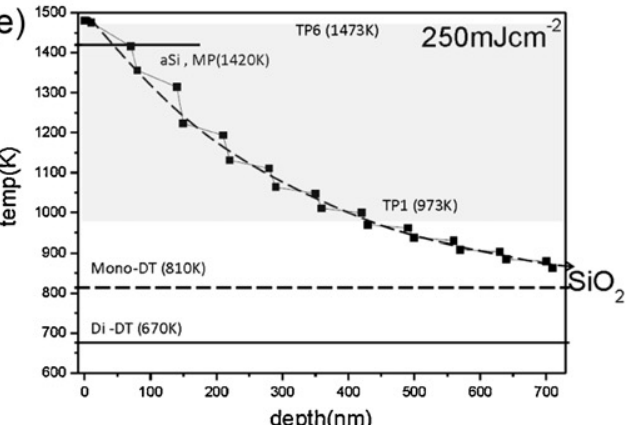

(g)

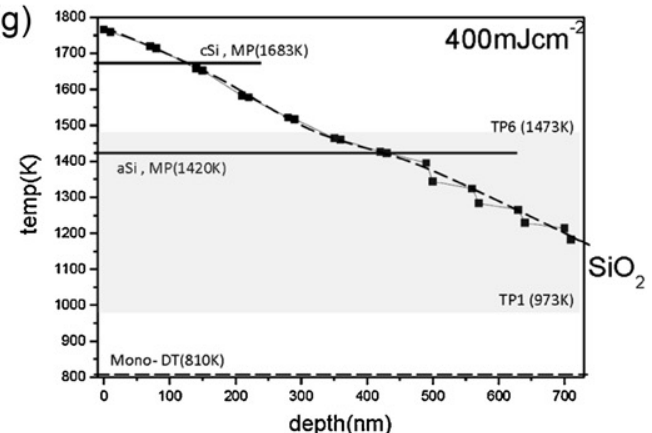

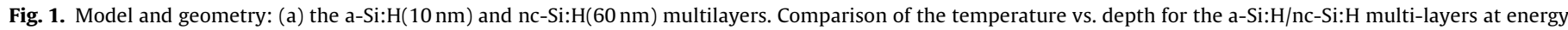

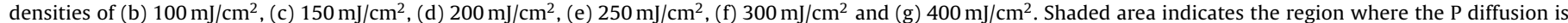
significant between $973 \mathrm{~K}$ (TP1), $1073 \mathrm{~K}$ (TP2), $1173 \mathrm{~K}$ (TP3), $1273 \mathrm{~K}$ (TP4), $1373 \mathrm{~K}$ (TP5) and $1473 \mathrm{~K}$ (TP6).

The laser energies needed for reaching mono- and didehydrogenation temperatures (DT) as well as the temperature range (TP1-TP6), where $P$ diffusion takes place inside the multistructure, are studied to evaluate if melting of single or multiple layers occurs. Thereby, we estimated the depth at which di-DT and mono-DT is reached, the diffusion depth of the P in the layers, as well as the possible melting depth (MD) in the multilayer structure (considering the a-Si:H melting point of $1420 \mathrm{~K}$ (a-Si MP) and $1683 \mathrm{~K}$ (c-Si MP) for doped nc-Si) as a function of the applied laser pulse energy density.

The numerical results are compared with experimental ones obtained from a multilayer with the above described structure deposited by hot wire chemical vapor deposition (HW-CVD) and annealed with $193 \mathrm{~nm}$ laser radiation of varying energy density and number of pulses.

\section{Statement of problem}

The high energy densities, provided by the short pulses of excimer laser (Lambda Physik LPX-220i), provoke locally rapid heating and cooling cycles in the a-Si:H and the nc-Si:H layers. Hence, the importance of a previous numerical approach to the experimental work, in order to carry out an adequate control of the induced temperature gradients by means of discrete energy density values.
To achieve this goal, we have taken into account that the target surface is completely covered by the laser spot which energy density $\left(\mathrm{W} / \mathrm{cm}^{2}\right)$ has been well theoretically fitted through the equation [22-25]:

$$
I_{i}(z, t)=I_{0}(\Phi, \tau)\left[1-R\left(n_{i}, k_{i}\right)\right] \exp \left[-\alpha_{i} z_{i}\right]
$$

where $I_{i}(z, t)$ describes the energy intensity profile in depth $(z)$ at any time $(t) ; I_{0}(\Phi, \tau)$ is the initial laser beam impinging perpendicular to the top a-Si:H film (see Fig. 1(a)), that in turn depends of the laser parameters: laser energy $\Phi\left(\mathrm{J} / \mathrm{cm}^{2}\right)$ and length pulse $\tau(s)$; $R\left(n_{i}, k_{i}\right)$ the reflectivity [26-29] and $n_{i}, k_{i}$ and $\alpha_{i}\left(\mathrm{~cm}^{-1}\right)$ the refraction, extinction index and absorption coefficient, respectively, at each consecutive interface $(i-)$ of the a-Si:H and doped nc-Si:H films; $z_{i}$ stands for the depth variable along each film.

The software ANSYS ${ }^{\circledR}$ based on FEM allows us to predict the temperature gradients and heat flux profiles by solving the one-dimensional heat conduction differential equation (HCDE) in depth:

$$
\begin{aligned}
& \rho(T) C(T) \frac{\partial T(z, t)}{\partial t}=\nabla[k(T) \nabla T(z, t)] \text { for } 300 \mathrm{~K} \leq T<T_{\mathrm{MP}}, \\
& \frac{\partial H(T)}{\partial t}=\nabla[k(T) \nabla T(z, t)] \quad \text { for } T \geq T_{\mathrm{MP}},
\end{aligned}
$$

where $T$ is the temperature field, $T_{\mathrm{MP}}$ the melting temperature and the thermal parameters: density $\rho\left(\mathrm{g} / \mathrm{cm}^{3}\right)$, specific heat $C(\mathrm{~J} / \mathrm{g} \mathrm{K})$, 
Table 1

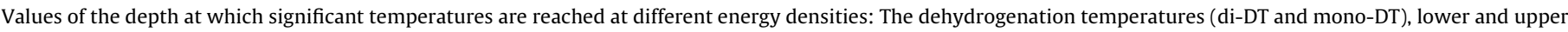
temperatures at which the P diffusion is significant (TP1 and TP6) and melting points (MP) of a-Si and nc-Si.

\begin{tabular}{|c|c|c|c|c|c|c|}
\hline$\Phi\left(\mathrm{mJ} / \mathrm{cm}^{2}\right)[\operatorname{depth}(\mathrm{nm})]$ & Di-DT (670 K) & Mono-DT (810 K) & TP1 (973 K) & a-Si MP (1420 K) & TP6 (1473 K) & c-Si MP (1683 K) \\
\hline 100 & 208 & 5 & & & & \\
\hline 150 & 610 & 220 & 70 & & & \\
\hline 200 & $>$ & 540 & 220 & & & \\
\hline 250 & $>$ & $>$ & 430 & 60 & 20 & \\
\hline 300 & $>$ & $>$ & 700 & 180 & 105 & \\
\hline 400 & $>$ & $>$ & $>$ & 420 & 330 & 120 \\
\hline
\end{tabular}

and thermal conductivity $k\left(\mathrm{~W} / \mathrm{cm}^{2} \mathrm{~K}\right)$, for each material, are temperature dependent and have been collected from the literature [30-34]. The variable $H\left(\mathrm{~J} / \mathrm{cm}^{3}\right)$ is the corresponding enthalpy function that accounts for any phase change that appears [25]. The HCDE system was completed by the following boundary conditions:

(a) the heat flux (above defined) normal to the irradiated surface:

$-k_{i}(T) \frac{\partial T}{\partial z}=I_{i}(z, t)$ for $t>0$

(b) the initial condition in the whole volume:

$T(z, 0)=T_{0} \quad$ for $t=0$

$T_{0}$ the room temperature of $300 \mathrm{~K}$.

\section{Numerical approach: results and discussion}

Fig. 1(b)-(g) shows a comparison of the temperature vs. depth for the a-Si:H/nc-Si:H multilayer on a $\mathrm{SiO}_{2}$ substrate (at $50 \mathrm{~mJ} / \mathrm{cm}^{2}$ and below, no temperatures of at least around di-DT are reached in the structures). The laser light energy applied on the surface increases first its temperature and produces a temperature gradient as the heat moves in depth. This gradient can be well fitted by an exponential or second degree polynomial function (the dashed line on Fig. 1(b)-(g)).

At $100 \mathrm{~mJ} / \mathrm{cm}^{2}$ the di-DT is reached down to a depth of $220 \mathrm{~nm}$; this value is also the threshold energy density necessary to reach the mono-DT on the surface. At $150 \mathrm{~mJ} / \mathrm{cm}^{2}$ the TP1 temperature ( $973 \mathrm{~K}$ ), where the P diffusion starts (as indicated in the caption of Fig. 1), reaches the first layer without any surface melting and the di-DT can be considered down to the 19th layer, while the mono-DT down to the 7th layer.

At $200 \mathrm{~mJ} / \mathrm{cm}^{2}$, TP1 reaches the 7th layer, whereas di-DT is extended to the whole multilayer structure and the mono-DT is reached around the 15th layer. The laser energy density of $250 \mathrm{~mJ} / \mathrm{cm}^{2}$ provokes melting in the first a-Si layer and the whole TP temperature range is attained (TP1(973 K)-TP6(1473 K)), from the upper limit TP6, affecting the 1st layer to the lower limit TP1, affecting down to the 13th layer. With $300 \mathrm{~mJ} / \mathrm{cm}^{2}$ the a-Si MP in the three first layers is reached.

Applying $400 \mathrm{~mJ} / \mathrm{cm}^{2}$, seven a-Si layers and the first nc-Si layer are totally molten, whereas the second one is partially molten. Therefore, an important increase of the Si crystalline fraction should be expected down to $135 \mathrm{~nm}$ depth.

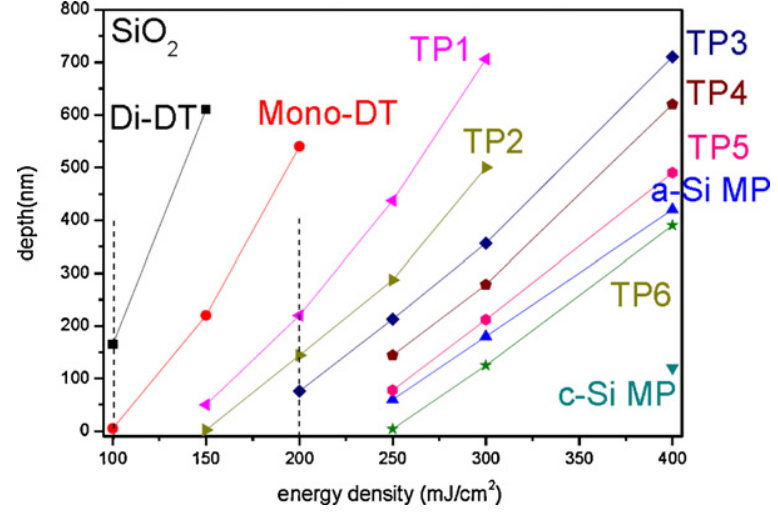

Fig. 2. Depth vs. energy density profiles at the dehydrogenation temperatures $670 \mathrm{~K}$ (di-DT), $810 \mathrm{~K}$ (mono-DT); P diffusion significant temperatures: $973 \mathrm{~K}$ (TP1), $1073 \mathrm{~K}$ (TP2), $1173 \mathrm{~K}$ (TP3), $1273 \mathrm{~K}$ (TP4), $1373 \mathrm{~K}$ (TP5) and $1473 \mathrm{~K}$ (TP6) and the a-Si:H $1420 \mathrm{~K}$ (a-Si MP) and $1683 \mathrm{~K}$ (nc-Si MP) melting points. Dashed lines indicate the experimental energies used in this work.

Table 1 summarizes the depth to which the di-DT and monoDT, TP1 to TP6, and a-Si and c-Si MPs temperatures have been reached. These results are also graphically illustrated on Fig. 2. The data points from this figure can be well fitted by second degree polynomial functions as the following:

$D=A_{0}+A_{1} \Phi+A_{2} \Phi^{2}$

where $D$ is the depth ( $\mathrm{nm}), \Phi$ is the energy density $\left(\mathrm{mJ} / \mathrm{cm}^{2}\right)$ and $A_{i}$ are the polynomial coefficients whose values are summarized in Table 2. These equations are very useful to optimize the experimental parameters prior to experimental work to predict easily and quickly the desired depth for a particular energy density, according to the threshold temperatures for the desired process.

In this way, we can estimate that $75<\Phi\left(\mathrm{mJ} / \mathrm{cm}^{2}\right)<180$ is the optimal range of energy density to anneal the multilayer structures in order to induce a di-dehydrogenation. Between $100<\Phi\left(\mathrm{mJ} / \mathrm{cm}^{2}\right)<255$ also mono-dehydrogenation takes place. Furthermore, up to $225 \mathrm{~mJ} / \mathrm{cm}^{2}$ melting of the first a-Si:H layers is produced. With respect to the $\mathrm{P}$ diffusion threshold temperature (TP1), it is expected to be reached around $125 \mathrm{~mJ} / \mathrm{cm}^{2}$. Above $225 \mathrm{~mJ} / \mathrm{cm}^{2}$ the whole TP1-TP6 range is fulfilled; thus, with increasing energy density, the P diffusion depth is also increased.

Table 2

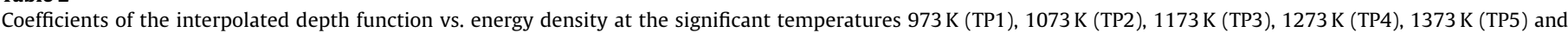
$1473 \mathrm{~K}$ (TP6).

\begin{tabular}{|c|c|c|c|c|c|c|c|c|c|}
\hline \multirow[t]{2}{*}{$\mathrm{SiO}_{2}$ substrate } & \multicolumn{9}{|c|}{ Temperature (K) } \\
\hline & (Di-DT) $670 \mathrm{~K}$ & (Mono-DT) $810 \mathrm{~K}$ & (TP1) $973 \mathrm{~K}$ & (TP2) $1073 \mathrm{~K}$ & (TP3) $1173 \mathrm{~K}$ & (TP4) $1273 \mathrm{~K}$ & (TP5) $1373 \mathrm{~K}$ & (a-Si MP) $1420 \mathrm{~K}$ & (TP6) $1473 \mathrm{~K}$ \\
\hline$A_{0}$ & -725 & -110 & -159.7 & -166.15 & -277 & -156 & -542 & -540 & -486 \\
\hline$A_{1}$ & 8.9 & -0.95 & -0.085 & -0.079 & 1.07727 & -0.0033 & 2.3133 & 2.4 & 1.57667 \\
\hline$A_{2}$ & $1 \mathrm{E}-14$ & 0.021 & 0.0099 & 0.0071 & 0.00347 & 0.0049 & 6.66667 & $-5.67 \mathrm{E}-17$ & 0.00153 \\
\hline
\end{tabular}



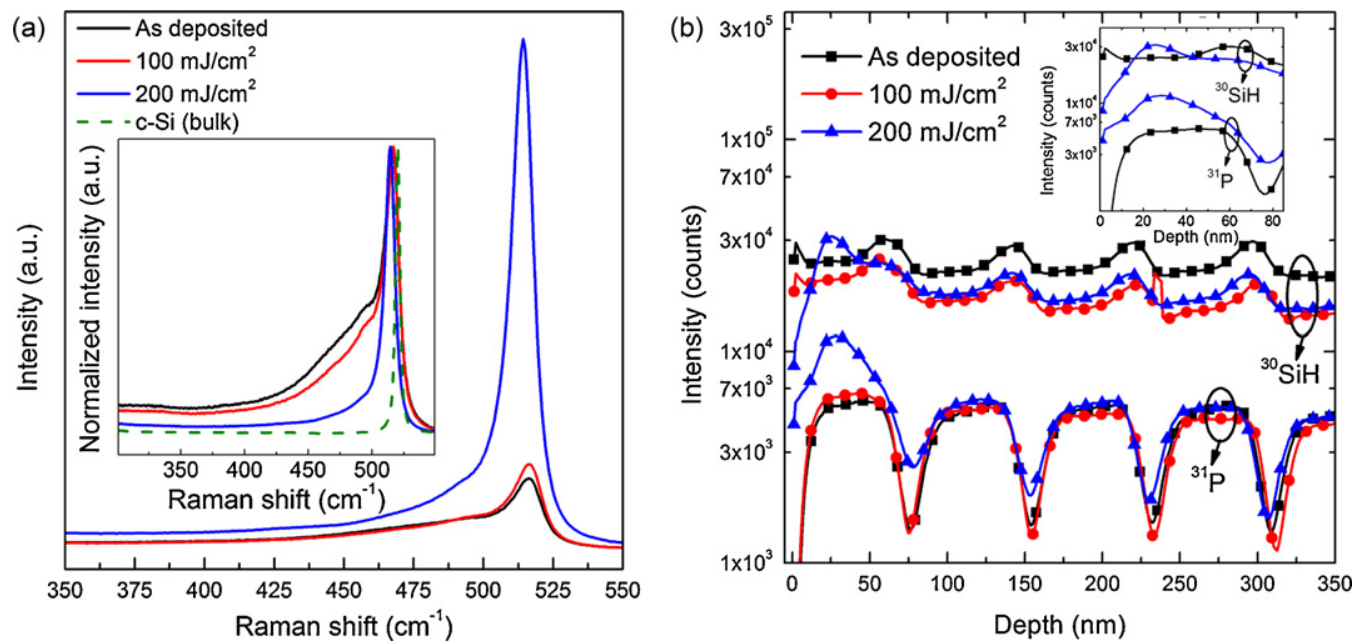

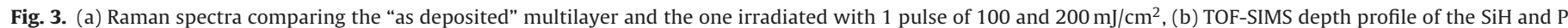
concentration for the "as deposited" multilayer and the one irradiated with 1 pulse of 100 and $200 \mathrm{~mJ} / \mathrm{cm}^{2}$. The inset shows a detailed view of the first $85 \mathrm{~nm}$.

\section{Experimental procedure: results and discussion}

The multilayer has been grown on glass substrate $(\sim 0.7 \mathrm{~mm}$ thickness) using HW-CVD at $150^{\circ} \mathrm{C}$ [35]. The UV-ELA set-up consists of a laser source, "in situ" controlled by an energy density attenuator. The original excimer laser spot possesses spatially inhomogeneous energy distribution, thus a fly-eye beam homogenizer (Exitech EX-HS-700D) has been used to obtain a uniformly distributed energy density on a $4 \mathrm{~cm} \times 2 \mathrm{~cm}$ spot, as described elsewhere [36]. The sample is positioned at the focus of the homogenizer optics on a motorized stage in helium atmosphere. In the following, results from samples irradiated with one pulse of 100 and $200 \mathrm{~mJ} / \mathrm{cm}^{2}$ is presented.

Raman spectroscopy was performed on the irradiated spots using $488 \mathrm{~nm}$ excitation wavelength. Raman laser power was kept well below the crystallisation threshold of a-Si:H. This excitation provides information on the overall structural changes of the upper layers (down to several hundred $\mathrm{nm}$ depth) in the multilayer structure TOF-SIMS analysis was used to determinate the depth distribution of $\mathrm{H}$ and $\mathrm{P}$ - concentration profiles.

Fig. 3(a) shows a comparison of the Raman spectra before and after UV-ELA. The spectrum of the as deposited sample shows the typical for a-Si broad band at around $480 \mathrm{~cm}^{-2}$ and a broad peak around $516 \mathrm{~cm}^{-2}$ related to the nanocrystalline silicon phase dispersed in a-Si matrix [37]. After 1 pulse of $100 \mathrm{~mJ} / \mathrm{cm}^{2}$ the intensity of the nc-Si peak slightly increases and the a-Si band decreases (Fig 3(a) inset). A greater improvement of the crystallinity is achieved with 1 pulse of $200 \mathrm{~mJ} / \mathrm{cm}^{2}$. The a-Si band intensity decreases significantly and the nc-Si feature converts to a sharp peak.

TOF-SIMS analysis (Fig. 3(b)) reveals that, in fact, 1 pulse of $100 \mathrm{~mJ} / \mathrm{cm}^{2}$ does not affect the $\mathrm{Si}-\mathrm{H}$ and $\mathrm{P}$ profile, being almost similar to the one from the deposited sample. The average intensity of the Si-H profile decreases from $\sim 28 \times 10^{3}$ to $\sim 20 \times 10^{3}$ counts that might be attributed to di-dehydrogenation. The sample irradiated with $200 \mathrm{~mJ} / \mathrm{cm}^{2}$ exhibits a reduction of the $\mathrm{Si}-\mathrm{H}$ content down to $30 \mathrm{~nm}$ in depth, i.e. of the first a-Si:H and nc-Si layers where, also mono-dehydrogenation should took place. Furthermore, for the same sample, the P concentration in the first $80 \mathrm{~nm}$ has almost doubled its value (from $5.5 \times 10^{3}$ to $11 \times 10^{3}$ counts at its maximum ( $30 \mathrm{~nm}$ depth)), i.e. of first a-Si:H and nc-Si layer. P has diffused in the first $3 \mathrm{a}-\mathrm{Si}: \mathrm{H}$ layers, where the slope of the $\mathrm{P}$ signal at the nc-Si:H/a-Si:H interface increases. These results are in quite reasonable agreement with the prediction of the numerical simulation.

\section{Conclusions}

The study has demonstrated that it is possible to perform a selective dehydrogenation and $\mathrm{P}$ diffusion in the multilayer-structure by excimer laser annealing.

The performed calculus indicate that the optimal energy densities to induce a di-dehydrogenation of the multi-layer film is in the range of $75<\Phi\left(\mathrm{mJ} / \mathrm{cm}^{2}\right)<180$ and to induce the monodehydrogenation in the range of $100<\Phi\left(\mathrm{mJ} / \mathrm{cm}^{2}\right)<255$. P diffusion (marked by temperature TP1 of $973 \mathrm{~K}$ ) starts for an energy density close to $125 \mathrm{~mJ} / \mathrm{cm}^{2}$, while for $225 \mathrm{~mJ} / \mathrm{cm}^{2}$ and greater, the temperatures between TP1 (973 K) to TP6 (1473 K) are totally fulfilled.

The depth vs. energy density at the significant temperatures DT, TP and MP can be well fitted by second degree polynomial functions in order to optimize the laser parameters prior to the experiments.

Lastly, estimated results have been compared with characterization of the experiment results of samples irradiated with 1 pulse of 100 and $200 \mathrm{~mJ} / \mathrm{cm}^{2}$ and it was possible to confirm the feasibility of UV-ELA to improve crystallisation grade of the multilayer.

\section{Acknowledgments}

This work was supported by MICINN: Virtuslaser-MAT200802350, Simbio-EUI2008-001177 and Xunta de Galicia: CESOLAS07REM007V11PR. We are very grateful and would like to thank E. Marins and M.F. Cerqueira from University of Minho for growing the multilayer structure.

\section{References}

[1] S. Sedky, A. Witvrouw, K. Baert, Sens. Actuators A: Phys. 97-98 (2002) 503-511.

[2] G. Fortunato, V. Privitera, A. La Magna, L. Mariucci, M. Cuscuna, B.G. Svensson, E. Monakhov, M. Camalleri, A. Magrì, D. Salinas, F. Simon, Thin Solid Films 504 $(1-2)(2006) 2-6$.

[3] J. Thiesen, H.M. Branz, R.S. Crandall, Appl. Phys. Lett. 77 (22) (2000) 3589.

[4] H. Jorge, H. Kibbel, F. Schaffler, H.J. Herzog, Thin Solid Films 183 (1989) 307.

[5] D.J. Eaglesham, H.J. Gossman, M. Cerullo, Phys. Rev. Lett. 65 (1990) 1227.

[6] J.J. Boland, Phys. Rev. B 44 (3) (1991) 1383.

[7] Q. Wang, C.W. Teplin, P. Stradins, B. To, K. Jones, H.M. Branz, J. Appl. Phys. 100 (2006) 1 .

[8] A. Martínez-Gil, A. Rota, T. Maroutian, B. Bartenlian, P. Beauvillain, E. Moyen, M. Hanbücken, Superlattices Microstruct. 36 (2004) 235

[9] P.M. Fahey, P.B. Griffin, J.D. Plummer, Rev. Mod. Phys. 61 (1989) 289

[10] R.N. Ghoshtagore, Phys. Rev. B 3 (2) (1971) 389.

[11] J. Pelleg, B.M. Ditchek, J. Appl. Phys. 73 (2)(1993) 699.

[12] F. Wittel, S. Dunham, Appl. Phys. Lett. 66 (11) (1995) 1415

[13] Y.M. Haddara, B.T. Folmer, M.E. Law, Appl. Phys. Lett. 77 (13) (2000) 1976.

[14] N.R. Zangenberg, J. Fage-Pedersen, J. Lundsgaard Hansen, A. Nylandsted Larsen, J. Appl. Phys. 94 (6) (2003) 3883. 
[15] G.L. McVay, A.R. DuCharme, Phys. Rev. B 9 (2) (1974) 627-631.

[16] F. Foulon, E. Fogarassy, A. Slaoui, C. Fuchs, S. Unamuno, P. Siffert, Appl. Phys. A 45 (1988) 361-364.

[17] S. de Unamuno, E. Fogarassy, Appl. Surf. Sci. 36 (1989) 1-11.

[18] S.C. Jain, J.R. Willis, R. Bullough, Adv. Phys. 39 (2) (1990) 127-190.

[19] R. Serna, A. Blanco, T. Missana, J. Solis, C.N. Afonso, A. Rodríguez, T. Rodríguez, M.F. da Silva, Appl. Phys. Lett. 68 (13) (1996) 1-3.

[20] P. Boher, J.L. Stehle, E. Fogarassy, Appl. Surf. Sci. 138-139 (1999) 199-205.

[21] H.J. Osten, Thin Solid Films 367 (2000) 101-111.

[22] J.C. Conde, P. González, F. Lusquiños, S. Chiussi, J. Serra, B. León, Appl. Surf. Sci. 248 (2005) 461.

[23] J.C. Conde, L. Fornarini, S. Chiussi, F. Gontad, P. González, B. Leon, S. Martelli, Thin Solid Films 517 (2008) 222.

[24] J.C. Conde, E. Martín, F. Gontad, S. Chiussi, L. Fornarini, B. Leon, Thin Solid Films 518 (2010) 2431.

[25] J.C. Conde, P. González, F. Lusquiños, B. Leon, Appl. Phys. A 95 (2009) 465.

[26] V.E. Borisenko, P.E. Hesketh, Rapid Thermal Processing of Semiconductors, Plenum Press, New York, 1997.
[27] J.C. Miller, R.F. Haglund (Eds.), Laser Ablation and Desorption, Academic Press, USA, 1998.

[28] L. Ward, The Constants of the Materials and Films, 2nd ed., IOP Publishing Ltd. Institute of Physics, London, 1994.

[29] E.D. Palik (Ed.), Handbook of Optical Constants of Solids, Academic Press, Inc., USA, 1985.

[30] S. DeUnamuno, E. Fogarassy, Appl. Surf. Sci. 36 (1989) 1.

[31] W. Szyszko, Appl. Surf. Sci. 90 (1995) 325.

[32] B. Abeles, Phys. Rev. 131 (5) (1963) 1096.

[33] J.P. Dismukes, L. Ekstrom, E.F. Steigmeier, I. Kudman, D.S. Beers, J. Appl. Phys. 35 (10) (1964) 2899

[34] V.M. Glazov, S.N. Chizhevskaya, N.N. Glagoleva, Liquid Semiconductors, Plenum Press, New York, 1969.

[35] S.A. Filonovich, M. Ribeiro, A.G. Rolo, P. Alpuim, Thin Solid Films 516 (2008) 576.

[36] E. López, S. Chiussi, J. Serra, P. González, B. León, Thin Solid Films 508 (2006) 48.

[37] Ch. Ossadnik, S. Veprl̈ek, I. Gregory, Thin Solid Films 337 (1999) 148. 